\title{
PENGEMBANGAN BAHAN KAMPAS REM SEPEDA MOTOR DARI KOMPOSIT SERAT BAMBU TERHADAP KETAHANAN AUS PADA KONDISI KERING DAN BASAH
}

\author{
Pramuko Ilmu Purboputro \\ Department of Mechanical Engineering, Universitas Muhammadiyah Surakarta \\ J1. A. Yani Tromol Pos 1 Pabelan, Kartasura, Surakarta 57102, Indonesia \\ Email:pip272@ums.ac.id
}

\begin{abstract}
ABSTRAK
Penelitian ini untuk menemukan komposisi bahan kampas rem yang optimal non asbes, yang mempunyai karakteristik dinamik yang lebih baik. Komposisi dilakukan dari serat bambu,fiberglass, serbuk aluminium, dengan pengikat poliester. Pengujian awal yang dilakukan adalah kekerasan bahan dan keausan pada kondisi kering dan pembasahan air. Hasil yang didapat adalah kampas rem dengan komposisi Variasi 1 adalah paling keras, dengan harga kekerasan sebesar 14,47 BHN yang lebih keras dibanding produk di pasaran dengan harga kekerasan 13,7 BHN. Pengujian Keausan Ogoshi pada kondisi kering maksimal mempunyai nilai keausan yang paling rendah yaitu sebesar $0.00041 \mathrm{~mm}^{2} / \mathrm{kg}$. Untuk Pengujian Keausan Ogoshi Kondisi basah dengan air, diperoleh bahwa, bahan kampas rem dengan Variasi 1 paling rendah keausannya yaitu sebesar 0,0062 $\mathrm{mm}^{2} / \mathrm{kg}$. Kondisi basah dengan oli, diperoleh bahwa, bahan kampas rem dengan Variasi 2 paling rendah keausannya yaitu sebesar 0,0003 $\mathrm{mm}^{2} / \mathrm{kg}$.
\end{abstract}

Kata kunci: kampas rem, serat bambu, kekerasasn, keausan.

\section{PENDAHULUAN}

Pemakaian kampas rem biasanya tidak lebih dari 10000 kali kontak pengeraman, artinya penggunaan dalam kota bisa jadi tidak lebih dari 6 bulan, apalagi terjadi keluhan umur yang lebih pendek akibat kampas rem ausnya tidak rata, sehingga pengereman tidak efektif atau tukar - tukar adaptor rem. Keausan tidak merata bisa diakibatkan tekanan yang kurang seragam, akibat pemasangan yang kurang tepat, misalnya terlalu kencang pada pinnya, sehingga pin bukan berfungsi sebagai pin, tetapi sepagai titik putar yang mati.

Kekuatan bahan komposit partikel rem, sangat dipengaruhi besar partikel,bahan matriknya dan proses pembuatannya. Kekuatan komposit partikel diperoleh maksimal pada ukuran 0,01 sampai 0,1 mm dan kekuatan surface bonding, pengepresan, dan sintering [1-2]. Proses tersebut sangat jarang dipaparkan para produsen kampas rem, sehingga perlu adanya penelitian tentang : bahan dan proses yang standar secara ilmiah agar kampas rem bisa mudah dibuat di negara kita, sehingga sangat perlu pengembangan penelitian ini secara terus menerus.

Penelitian ini menggunakan serat bambu, fiber glass, dan serbuk alumuniam (Al) bermatriks polyester akan diuji kekuatannya dengan metode pengujian kekuatan gesek (Ogoshi) dan pengujian kekuatan kekerasan (Brinell). dan juga foto makro, dan pengujian karakteristik pengeremannya. 


\section{RUMUSAN MASALAH}

Keausan tidak merata bisa diakibatkan tekanan yang kurang seragam, akibat pemasangan yang kurang tepat, misalnya terlalu kencang pada pinnya, sehingga pin bukan berfungsi sebagai pin , tetapi sebagai titik putar yang mati, dan adanya konyribusi ketahanan aus dan kekerasan bahan rem .

Kekuatan bahan komposit partikel rem, sangat dipengaruhi besar partikel,bahan matriknya dan proses pembuatannya. Kekuatan komposit partikel diperoleh maksimal pada ukuran 0,01 sampai 0,1 mm dan kekuatan surface bonding, pengepresan, dan sintering [1-2]. Proses tersebut sangat jarang dipaparkan para produsen kampas rem, sehingga perlu adanya penelitian tentang : bahan dan proses yang standar secara ilmiah agar kampas rem bisa mudah dibuat di negara kita, sehingga sangat perlu pengembangan penelitian bahan kampas rem ini secara terus menerus.

\section{TUJUAN DAN MANFAAT PENELITIAN}

\section{Tujuan Penelitian}

1. Mengembangkan hasil penelitian tahun I yaitu tingkat keausan bahan kampas rem, dengan menggunakan variasi komposisi dari serat bambu, fiber glass, serbuk aluminium (Al), dengan matriks polyester, dengan hasil terbaik kekerasan dan keausan pada komposisi :

a. $\quad 40 \%$ serat bambu $+10 \%$ fiber glass $+10 \%$ aluminium $(\mathrm{Al})+40 \%$ polyester

b. $30 \%$ serat bambu $+15 \%$ fiber glass $+15 \%$ aluminium $(A l)+40 \%$ polyester

c. $20 \%$ serat bambu $+20 \%$ fiber glass $+20 \%$ aluminium $(\mathrm{Al})+40 \%$ polyester, yang akan dijadikan prototype kampas rem sepeda motor.

2. Meneliti karakteristik pengeremannya, dengan uji dynamometer, sehingga diperoleh parameter penegereman, daya serap pengereman, jarak penegereman, koefisien gesek kampas rem. Pada variasi pengujian koefisien gesek, pada keadaan kering (udara) dan keadaan basah ( air dan oli).

\section{Manfaat Penelitian}

1. Melakukan penelitian terapan yang hasilnya diharapkan secara jangka panjang di negara Indonesia agar tidak ketergantungan lagi dengan komponen mesin dari luar terutama kampas rem, dan sekaligus memanfaatkan daur ulang dan potensi alam yang ada di lingkungan sekitar kita serta lebih aman bagi kesehatan.

2. Mendukung komponen Tornas (Motor Nasional) atau Mobnas (Mobil Nasional) dalam hal pengembangan kampas rem kendaraan.

\section{TINJAUAN PUSTAKA}

Irfan, Pramuko IP, Ngafwan (2009) [3], melakukan penelitian tentang kampas rem gesek dengan memberikan waktu sintering pada tekanan kompaksi sebesar 10 menit. Keausan suatu bahan komposit semakin besar atau semakin mudah aus dapat dipengaruhi oleh besarnya waktu yang diberikan pada proses kompaksi. Bila waktu penekanannya semakin besar maka tingkat keausan pun juga semakin besar. Nilai kekerasan suatu bahan juga terpengaruh oleh besar waktu penekanan kompaksi yang diberikan dalam proses pembuatan bahan kampas rem. Dalam pembuatan kampas, nilai kekerasan kampas juga berpengaruh dengan semakin besar kompaksi yang dibebankan maka semakin keras pula komposit tersebut. Karena komposit tersebut sendiri dipengaruhi oleh beberapa faktor dalam proses pembuatan dari bahan menjadi komposit dan beberapa penyebabnya yaitu: variasi bahan, beban kompaksi yang diberikan serta lamanya beban kompaksi, dan pemanasan (sinter).

Karakteristik dengan tingkat keausan rendah dan Brinell Hardness Number (BHN) 
tinggi diperoleh dengan memberikan tekanan pembentukan relatif lebih rendah dibanding spesimen lainnya [4]. Hal ini disebabkan oleh dua kemungkinan:

1. Terpisahnya resin sebagai bahan pengikat (binder) dari campuran komposit.

2. Kekuatan ikat resinlebih kecil dari pada tekanan pembentukan yang diberikan pada specimen pada waktu proses pembuatan spesimen.

Imam, Pramuko I.P (2009) [5], melakukan penelitian tentang kampas rem gesek dengan memberikan peningkatan sintering . Dengan semakin tinggi suhu sintering berpengaruh pada tingkat keausan. Jika semakn tinggi suhu sinteringnya maka menyebabkan nilai keausan meningkat. Maka keausan semakin tinggi. Peningkatan suhu sintering juga berpengaruh pada kekerasan kampas. Semakin tinggi suhu sinteringnya maka nilai kekerasannya akan semakin menurun. Bahan komposit sebenarnya banyak sekali terdapat di alam, karena bahan komposit bisa terdiri dari organik dan anorganik seperti bambu, kayu, daun, dan sebagainya. Secara tidak sadar sebenarnya kita telah mengenal berbagai jenis komposit. Seseorang memperkuat tanah liat dengan jerami, merupakan komposit yang sudah lama dikenal.

\section{METODE PENELITIAN}

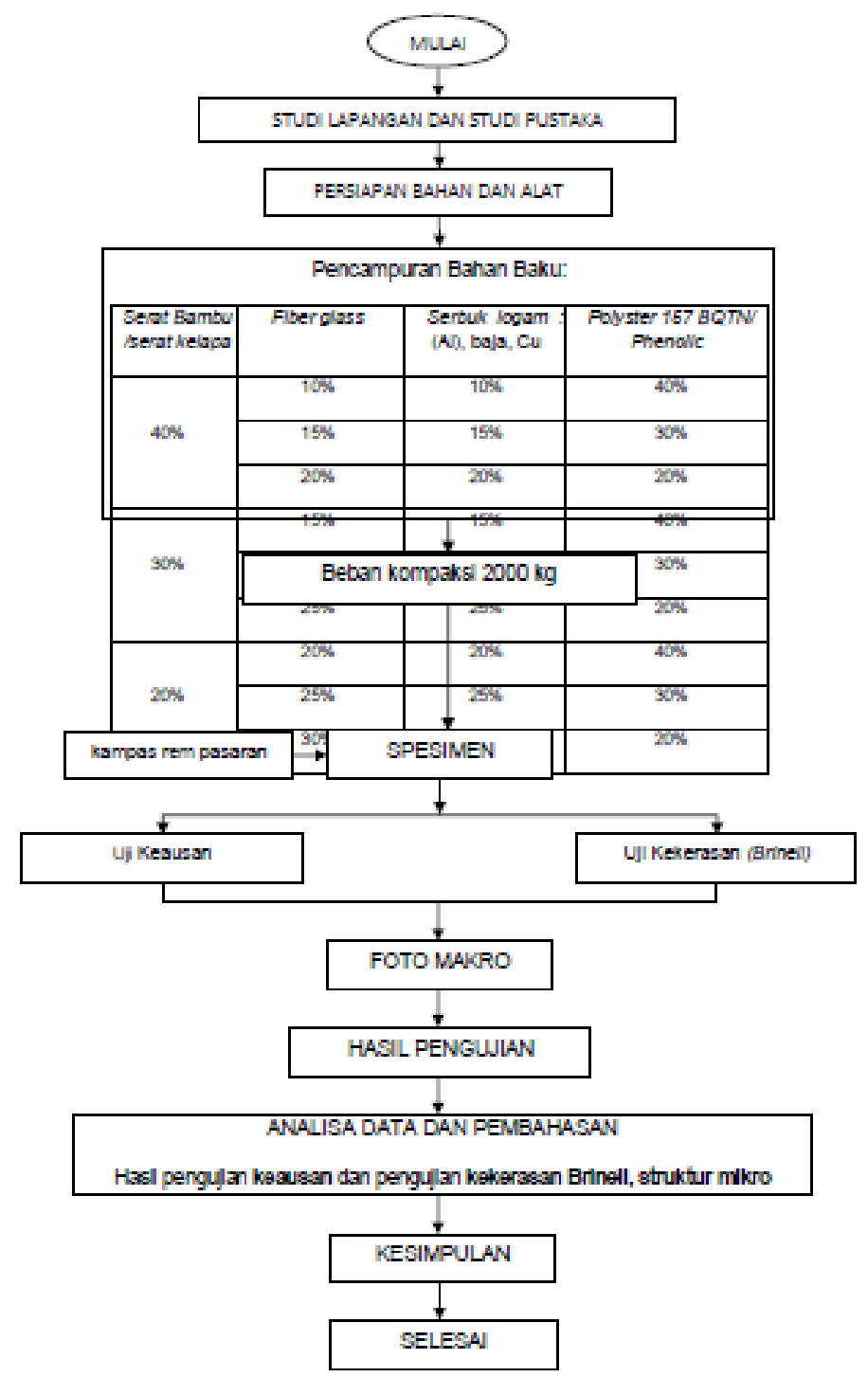

Gambar 1. Langkah Penelitian 
ISSN: 1411-4348

\section{HASIL PENGUJIAN}

Kekerasan

$\mathrm{BHN}=\frac{2 \mathrm{P}}{\pi \mathrm{D}\left(\mathrm{D}-\sqrt{D^{2}-d^{2}}\right)}$

Dimana:

$\mathrm{BHN}=$ Brinell Hardness Number,

$\mathrm{P} \quad=$ Gaya Tekan $(15.625 \mathrm{~kg})$

$\mathrm{D} \quad=$ Penetrator diameter $(2.5 \mathrm{~mm})$

$\mathrm{d} \quad=$ diameter injakan $(\mathrm{mm})^{2}$

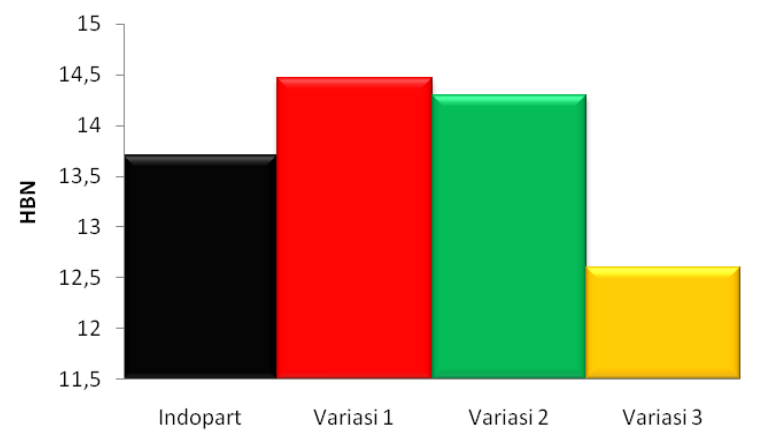

Gambar.2. Harga Kekerasan Variasi Kampas Rem.

\section{Pengujian Keausan Ogohosi Wear Test}

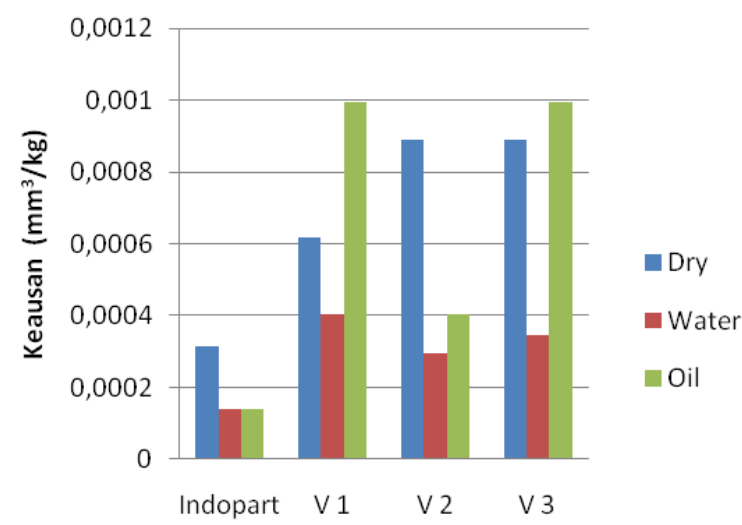

Gambar 3. Grafik Hasil Pengujian Keausan Oghosi Untuk berbagai MediaPembasahan Pengereman

\section{Pengujian Keausan Wiprotest}

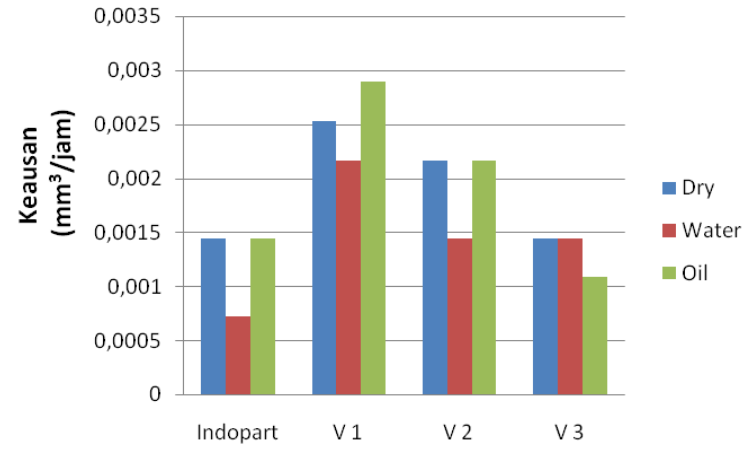

Gambar 4. Perbandingan Harga Keausan Wipro untuk Berbagai Media Pembasahan 


\section{KESIMPULAN DAN SARAN \\ Kesimpulan}

Dari data, hasil dan pembahasan, maka dapat ditarik kempulan bahwa:

1. Untuk Pengujian Kekerasan, maka bahan kampas rem dengan komposisi Variasi 1 adalah paling keras, dengan harga kekerasan sebesar 14,47 BHN yang lebih keras dibanding produk di pasaran dengan harga kekerasan 13,7 BHN

2. Untuk Pengujian Keausan Ogoshi pada kondisi kering, maka bahan kampas rem dengan Variasi 2, mempunyai nilai keausan yang paling rendah yaitu sebesar $0.00041 \mathrm{~mm}^{2} / \mathrm{kg}$, yang sedikit lebih besar dari produk di pasaran dengan keausan sebesar $0.00014 \mathrm{~mm}^{2} /$ kg. Untuk Pengujian Keausan Ogoshi Kondisi basah dengan air, diperoleh bahwa, bahan kampas rem dengan Variasi 1 paling rendah keausannya yaitu sebesar $0,0062 \mathrm{~mm}^{2} / \mathrm{kg}$, namun masih lebih tinggi sedikit dari bahan kampas rem pasaran yaitu sebesar 0,0032 $\mathrm{mm}^{2} / \mathrm{kg}$. Dan Pengujian Keausan Ogoshi Kondisi basah dengan oli, diperoleh bahwa, bahan kampas rem dengan Variasi 2 paling rendah keausannya yaitu sebesar 0,0003 $\mathrm{mm}^{2} / \mathrm{kg}$, namun masih lebih tinggi sedikit dari bahan kampas rem pasaran yaitu sebesar $0,00014 \mathrm{~mm}^{2} / \mathrm{kg}$

3. Untuk Pengujian Keausan Wipro pada kondisi kering, maka bahan kampas rem dengan Variasi 3, mempunyai nilai keausan yang paling rendah yaitu sebesar $0.00014 \mathrm{~mm}^{2} / \mathrm{kg}$ , yang sama dari produk di pasaran dengan keausan sebesar $0.00014 \mathrm{~mm}^{2} / \mathrm{kg}$. Untuk Pengujian Keausan Wipro Kondisi basah dengan air, diperoleh bahwa, bahan kampas rem dengan Variasi 2 dan 3 paling rendah keausannya yaitu sebesar $0,0014 \mathrm{~mm}^{2} / \mathrm{kg}$, namun masih lebih tinggi sedikit dari bahan kampas rem pasaran yaitu sebesar 0,0007 $\mathrm{mm}^{2} / \mathrm{kg}$. Dan Pengujian Keausan Wipro Kondisi basah dengan oli, diperoleh bahwa, bahan kampas rem dengan Variasi 3 paling rendah keausannya yaitu sebesar 0,0011 $\mathrm{mm}^{2} / \mathrm{kg}$, namun masih lebih tinggi sedikit dari bahan kampas rem pasaran yaitu sebesar $0,00014 \mathrm{~mm}^{2} / \mathrm{kg}$

\section{Saran}

Dari kesimpulan dapat direkomendasi-kan bahwa bahan kampas rem dengan variasi 1 atau 2 dapat dijadikan alternatif bahan kampas rem yang mendekati karakteristik di pasaran.

\section{DAFTAR PUSTAKA}

[1] F. Thumler, 1993. Powder Metalurgy. Institute Of Material, London.

[2] German, R.M., 1984. Powder Metallurgy Science. Metal Powder Industries Federation. Princeton, New Jersey.

[3] Irfan, Pramuko, 2009, Pengaruh Variasi Tekanan Kompaksi Terhadap Ketahanan Kampas Rem Gesek Sepatu. Laporan Tugas Akhir Fakultas Teknik Mesin UMS, Agustus 2009, Surakarta.

[4] Blau J. Peter, Compositions, Functions, and Testing of Friction Brake Materials and Their Additives, U.S. DEPARTMENT OF ENERGY, August 2001.

[5] Imam Setiyanto, Pramuko, 2009. Pengaruh Variasi Temperatur Sintering Terhadap Ketahanan Aus Bahan Rem Gesek Sepatu. Laporan Tugas Akhir Fakultas Teknik Mesin UMS, Agustus 2009, Surakarta. 